\title{
Hydrogen embrittlement of structural steels: Effect of the displacement rate on the fracture toughness of high-pressure hydrogen pre-charged samples
}

\author{
G. Álvarez ${ }^{1}{ }^{*}$, L.B. Peral ${ }^{1}$, C. Rodríguez ${ }^{1}$, T.E. García ${ }^{1}$, F.J. Belzunce ${ }^{1}$ \\ ${ }^{1}$ SIMUMECAMAT research group, University of Oviedo, West Building, 7.1.17. University Campus, 33203 \\ Gijón, Spain. Email*: uo224369@uniovi.es
}

\begin{abstract}
The aim of this paper is to study the effect of the displacement rate on the fracture toughness under internal hydrogen of two different structural steels grades used in energy applications. To this end, steel specimens were pre-charged with gaseous hydrogen at $19.5 \mathrm{MPa}$ and $450^{\circ} \mathrm{C}$ for 21 hours. Permeation experiments were also conducted to obtain the hydrogen diffusion coefficients. It was observed that the lower the displacement rate and the higher the steel yield strength, the stronger the reduction in fracture toughness due to the presence of internal hydrogen. A change in the fracture micromechanism was also detected. All these findings were justified in terms of hydrogen diffusion and accumulation in the crack front region in the different specimens.
\end{abstract}

Keywords: Hydrogen embrittlement, fracture toughness, hydrogen diffusion, structural steels

\section{Introduction}

Hydrogen embrittlement is a phenomenon of degradation of the mechanical properties of metallic components, such as vessels or pipes in the power industry, marine off-shore platforms and hydrogen powered vehicles, when they are exposed to aggressive hydrogen atmospheres during their in-service life [1-5]. The exposure of structural components to hydrogen atmospheres or to acid aqueous media can increase the risk of failure due to hydrogen ingress and its interaction with the material'microstructure when simultaneously submitted to mechanical loads.

Hydrogen is presently considered a future alternative energy source to fossil fuels, with commercial fuel cell vehicles and hydrogen refuelling stations currently being under construction in many countries. The selection of suitable steels able to resist in-service loads under high hydrogen pressures for long periods of time is hence a necessity. Therefore, broad-ranging, in-depth studies are still needed to design specific steels and define maximum loads and environmental conditions in order to safely construct such infrastructures.

It is now known that hydrogen embrittlement of structural steels increases with steel yield strength, although this effect is also dependent on the microstructure of the steel [6-9]. Thus, precipitates, inclusions, dislocations, grain boundaries, etc. constitute common reversible or irreversible hydrogen traps [10-13], which affect hydrogen solubility and diffusion, and their role can be critical in resisting hydrogen embrittlement.

Several methodologies have been used for decades to analyse hydrogen embrittlement. The most common technique is the slow strain rate tension test (SSRT) [14-16]. The results of these tests are usually represented as embrittlement indexes (El\%), related to the strength or the reduction in area of the specimens tested with and without hydrogen. In such tests, a decrease in ductility due to the presence of hydrogen is usually detected, while the strength properties are generally barely affected [17]. On the other hand, fracture toughness is a very important property in the design of large steel components, where the presence of tiny non-detected cracks is unavoidable. This material property is substantially affected by the presence of hydrogen, as the existence of cracks give rise to high local hydrostatic stresses which attract hydrogen atoms, thus favouring embrittlement reactions. Fracture toughness tests performed on electrochemically pre-charged specimens submerged in specific acid media are used to analyse this phenomenon. However, these kinds of tests are usually too aggressive compared to gaseous hydrogen tests [18-20]. Furthermore, such electrochemically pre-charged tests do not represent the real in-service conditions of components loaded under 
hydrogen gas pressure. It is also quite difficult to determine the amount of hydrogen introduced in the material in these cases. Moreover, in order to gain a clearer view of the embrittlement phenomena detected in these fracture toughness tests, it is essential to determine the hydrogen content in the specimen during the fracture test, and also to know the hydrogen diffusivity at the test temperature. In the latter case, the use of complementary permeation experiments is considered highly recommendable [21-24].

In the present study, fracture toughness tests in air at room temperature (RT) using specimens pre-charged with hydrogen in a high-pressure reactor were performed on two structural steels with different microstructures and strength levels. Hydrogen embrittlement was quantified in terms of fracture toughness, the effect of the applied test displacement rate was analysed, and their failure micromechanisms determined $[25,26]$. Finally, the results were justified on the basis of the steel microstructure, hydrogen diffusivity and hydrogen accumulation in the region located ahead of the specimen pre-crack.

\section{Materials and Methods}

\subsection{Materials and tensile properties}

Two different steel plates were used in this study: a structural S355 steel with a thickness of 30 $\mathrm{mm}$, and a quenched and tempered $\left(30 \mathrm{~min}\right.$ at $600^{\circ} \mathcal{C ~ H 8}$ steel with a thickness of $35 \mathrm{~mm}$. The chemical compositions of the two steels are shown in Table 1.

Table 1. Chemical composition of the steels (wt \%)

\begin{tabular}{ccccccccc}
\hline Material & $\% \mathrm{C}$ & $\% \mathrm{Mn}$ & $\% \mathrm{Si}$ & $\% \mathrm{Cr}$ & $\% \mathrm{Cu}$ & $\% \mathrm{Ni}$ & $\% \mathrm{Mo}$ & $\% \mathrm{~V}$ \\
\hline S355 & 0.13 & 0.8 & 0.26 & 1.58 & 0.27 & 0.25 & 0.05 & - \\
H8 & 0.15 & 0.25 & 0.25 & 1.58 & 0.13 & 3.05 & 0.55 & 0.05 \\
\hline
\end{tabular}

The tensile properties of the two steels were determined at room temperature according to the UNE-EN-ISO 6892 standard [27], using standard round-bar specimens with a calibrated length of 70 $\mathrm{mm}$ and a diameter of $10 \mathrm{~mm}$. These tests were performed only on uncharged specimens at room temperature under a displacement rate of $1 \mathrm{~mm} / \mathrm{min}$.

\subsection{Hydrogen permeation and high pressure pre-charging test}

To better understand the influence of hydrogen on these steels, the effective hydrogen diffusion

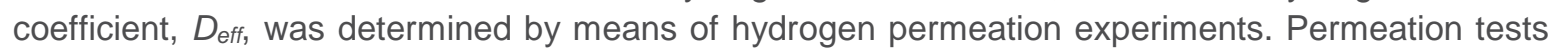
were performed at room temperature using a double electrolytic cell with two compartments. The hydrogen permeation specimens had a diameter of $20 \mathrm{~mm}$ and a thickness of $1 \mathrm{~mm}$. Each specimen was electrical discharge machined from the steel plates and ground using 1200 grit abrasive paper. The specimens were then one-sided plated with $\mathrm{Pd}$ to enhance hydrogen oxidation at the hydrogen exit cell.

a)

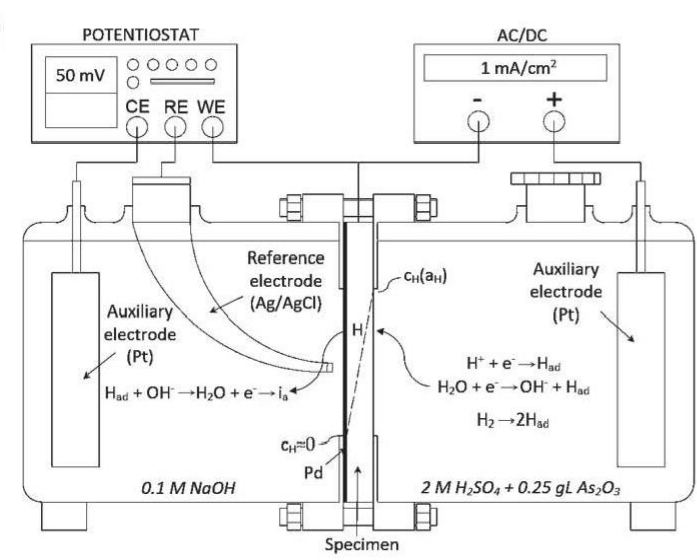

b)

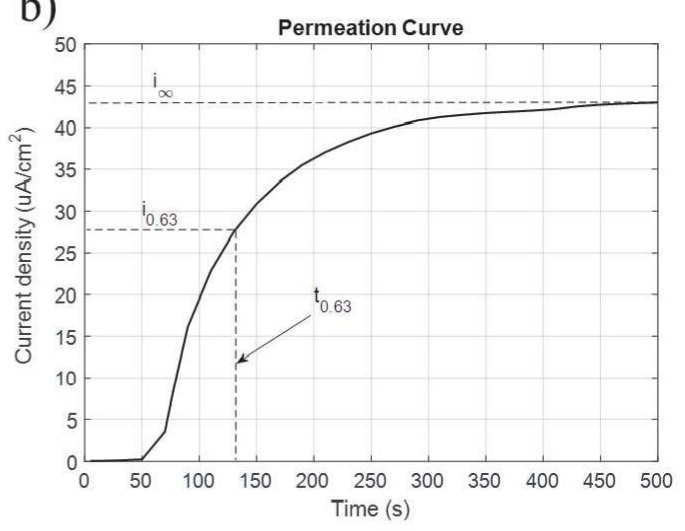

Figure 1. a) Hydrogen permeation cell. b) Typical permeation curve 
The hydrogen permeation setup consisted of separate charging and oxidation cells, a reference electrode $(\mathrm{Ag} / \mathrm{AgCl}$ or SSC), two auxiliary Pt electrodes, and a potentiostat (Figure 1a). The specimen, with an exposed surface area of $1 \mathrm{~cm}^{2}$, was mounted between the two compartments. The charging cell was galvanostatically polarized at a constant charging current density of $1 \mathrm{~mA} \mathrm{~cm}$ in $2 \mathrm{M} \mathrm{H}_{2} \mathrm{SO}_{4}$ solution with $0.25 \mathrm{~g} / \mathrm{A} \mathrm{As}_{2} \mathrm{O}_{3}$ (hydrogen poison to facilitate the dissociation of the $\mathrm{H}_{2}$ molecule into atomic hydrogen). On the detection or oxidation side of the double cell, the sample was potentiostatically maintained at a constant potential of $50 \mathrm{mV}$ versus the SSC reference electrode in a $0.1 \mathrm{M} \mathrm{NaOH}$ solution.

The evolution of the anodic current density over time (Figure $1 \mathrm{~b}$ ) until reaching a steady-state value, $i_{\infty}\left(\mu A \cdot m^{-2}\right)$, was measured to determine the diffusion coefficient, $D_{\text {eff }}\left(\mathrm{m}^{2} / \mathrm{s}\right)$, using the time lag method (1) derived from Fick's second law. The apparent subsurface diffusible hydrogen concentration at the charging side, $C_{\text {eff, }}$ may likewise be estimated according to the ASTM G148 standard [28] by means of Expression (2).

$$
\begin{aligned}
& D_{\text {eff }}=\frac{d^{2}}{6 t_{0.63}} \\
& C_{\text {eff }}=\frac{i_{\infty} d}{D_{\text {eff }}}
\end{aligned}
$$

In the above equations, $\mathrm{F}\left(96485 \mathrm{C} \mathrm{mo}^{1}\right)$ is Faraday's constant, $\mathrm{d}(\mathrm{m})$ is the specimen thickness, and $t_{0.63}(\mathrm{~s})$ is the lag time, defined as the elapsed time at $\mathrm{i}(\mathrm{t}) / \mathrm{i}_{\mathrm{o}}=0.63$ (Figure $1 \mathrm{~b}$ ).

In order to determine the effect of pre-charged hydrogen on the fracture behaviour of the steels, some specimens were pre-charged with gaseous hydrogen in a high-pressure reactor. A hydrogen pressure of $19.5 \mathrm{MPa}$ was applied for 21 hours at $450^{\circ} \mathrm{C}$. Subsequently, in order to avoid hydrogen egress, the hydrogen pre-charged specimens were stored in liquid nitrogen, where they were kept until the start of the fracture tests. In addition, with the aim of determining the concentration of hydrogen in both steels at the beginning of the tests $\left(\mathrm{C}_{\mathrm{HO}}\right)$, cylindrical pins of the two steels were pre-charged at the same time as the fracture specimens. After the pre-charge, these samples measuring $10 \mathrm{~mm}$ in diameter and $30 \mathrm{~mm}$ in length ( 20 g mass) were introduced into a LECO DH603 hydrogen analyser and their hydrogen contents were measured.

\subsection{Fracture Toughness Tests}

Fracture toughness tests were carried out using three-point bending $S E(B)$ specimens with the following dimensions: $17.5 \times 10 \times 80 \mathrm{~mm}^{3}$ (Figure 2a). In accordance with the ASTM E1820 standard [29], specimens were fatigue pre-cracked at ambient temperature $(R=0.1)$ until obtaining a crack length-to-width ratio $\mathrm{a} / \mathrm{W} \equiv 0.5$ and were subsequently side-grooved to obtain a final net-thickness, $\mathrm{B}_{\mathrm{N}}$, of $7.3 \pm 0.05 \mathrm{~mm}$. Then, some specimens were hydrogen pre-charged following the previously reported procedure. Pre-charged specimens were extracted from the liquid nitrogen a few minutes before the beginning of the test, which commenced when the centre of the specimen reached room temperature.

a)

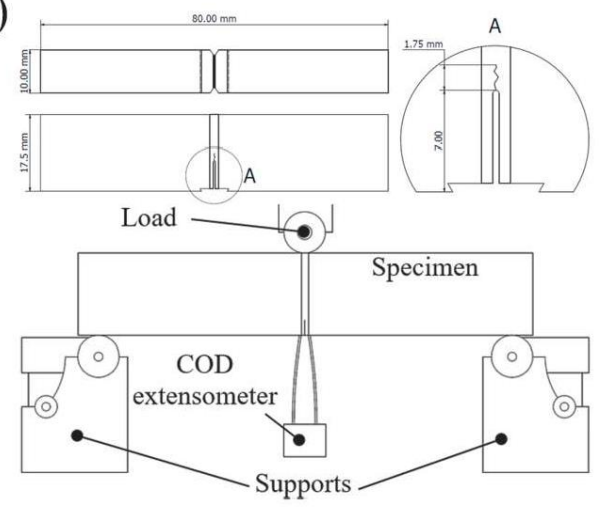

b)

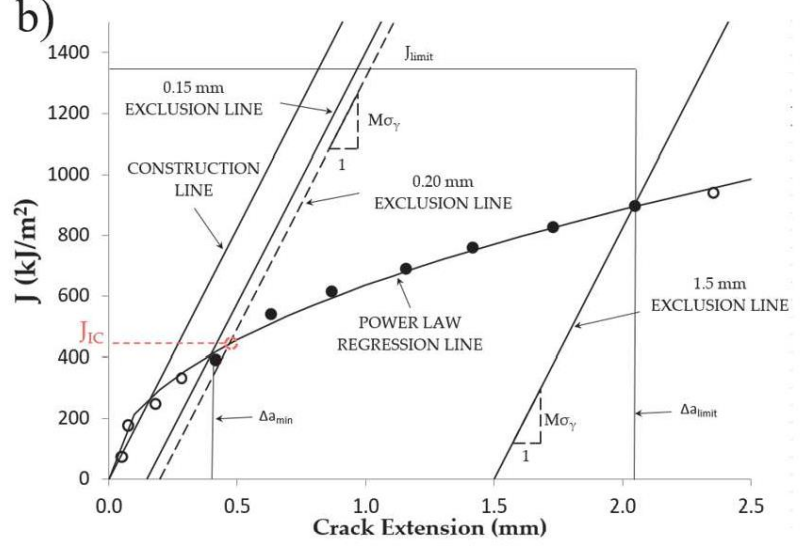


Figure 2. Fracture toughness tests. a) Specimen dimensions and loading fixture, b) J-R curve construction

The single-specimen method based on the elastic unloading compliance technique was used to determine all the $\mathrm{J}-\boldsymbol{\Delta} \mathrm{a}(\mathrm{J}-\mathrm{R})$ curves under standard laboratory conditions. Fracture toughness values, JIC, for an effective crack growth of $0.2 \mathrm{~mm}$, in accordance with the ASTM E1820 standard [29], were calculated from these curves after a power regression line fitting procedure (Figure $2 \mathrm{~b}$ ). In addition to the standard test displacement rate used for testing the specimens without hydrogen $(v=$ $0.1 \mathrm{~mm} / \mathrm{min}$ ), hydrogen pre-charged specimens were also tested under lower displacement rates ( 0.01 and $0.001 \mathrm{~mm} / \mathrm{min}$ ) in order to observe the effect of the loading rate on hydrogen embrittlement. Once the $\mathrm{J}_{\mathrm{I}}$ fracture toughness values under each tested condition were obtained, the following hydrogen embrittlement index, $\mathrm{HEI}(\%)$, was used to quantify hydrogen embrittlement:

$$
\operatorname{HEI}(\%)=\frac{J_{I C}-J_{I C H}(v)}{J_{I C}}
$$

where $\mathrm{J}_{\mathrm{IC}}$ is the fracture toughness of the steel without hydrogen, and $\mathrm{J}_{\mathrm{ICH}}(\mathrm{V})$ is the fracture toughness corresponding to the hydrogen pre-charged samples tested at the corresponding displacement rate (v). Moreover, the slope of the J-R curves was also calculated in these tests as the $\mathrm{J}$ increment needed for the crack to grow $1 \mathrm{~mm}$, from 0.5 to $1.5 \mathrm{~mm}$.

The fracture surfaces were finally analysed under a scanning electron microscope (SEM JEOLJSM5600). The following parameters were used: acceleration voltage of $20 \mathrm{kV}$ and working distance range of $40-50 \mathrm{~mm}$.

\section{Results and discussion}

\subsection{Microstructure and tensile properties}

The microstructures of the analysed steels are shown in Figure 3. The structural S355 steel had a ferritic-pearlitic microstructure (Figure 3a), while the microstructure of the $\mathrm{H} 8$ steel was tempered martensite (Figure $3 b$ ). The carbide precipitation that took place during the tempering stage of $\mathrm{H} 8$ is also clearly seen in Figure 3b).
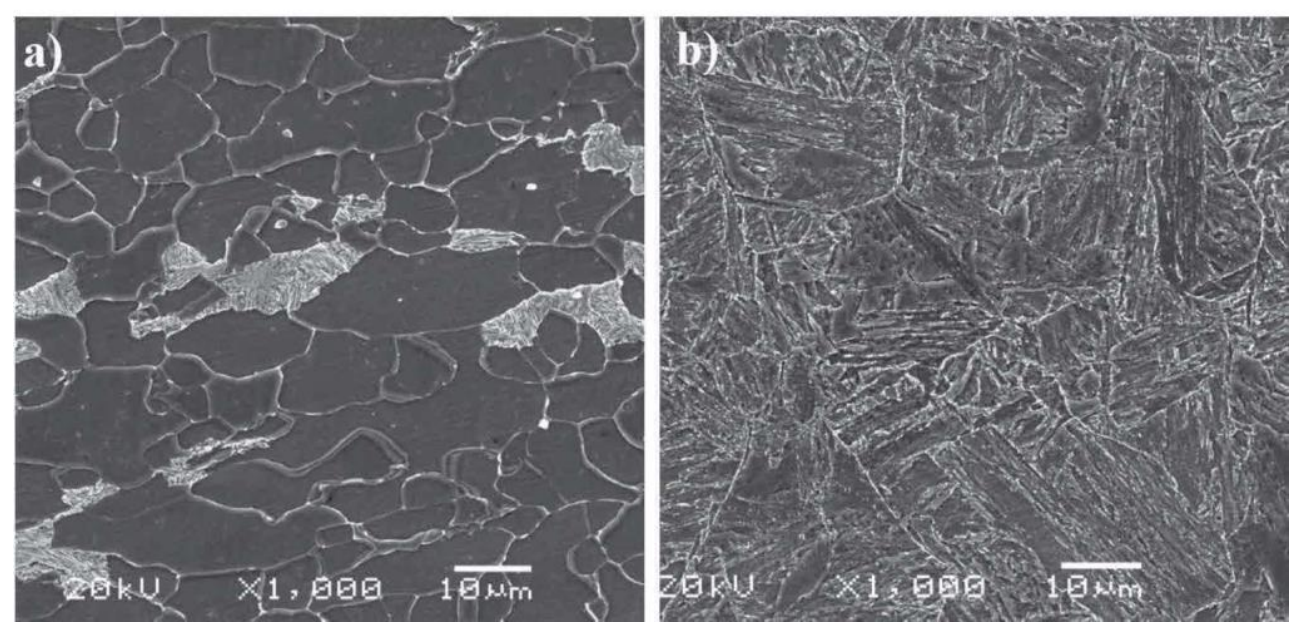

Figure 3. Microstructure of the steels: a) S355, b) H8

Microstructural differences between the two steels can also be noticed in the hardness and room temperature tensile properties shown in Table 2. As expected, the Brinell hardness, HB, yield stress, $\sigma_{y s}$ and ultimate tensile strength, $\sigma_{\text {uts, }}$ of the $\mathrm{H} 8$ steel are higher than those corresponding to the S355 steel, while the opposite occurs with tensile elongation, e, and reduction of area, RA.

\begin{tabular}{cccccc}
\hline Steels & HB & $\sigma_{y s}(\mathrm{MPa})$ & $\sigma_{\text {uts }}(\mathrm{MPa})$ & $\mathrm{e}(\%)$ & $\mathrm{RA}(\%)$ \\
\hline S355 & 145 & 390 & 540 & 32 & 77 \\
\hline
\end{tabular}


$\mathrm{H} 8$

285

790

860

21

68

Table 2. Hardness and room temperature tensile properties of the steels

\subsection{Hydrogen permeation}

Table 3 gives the estimated values of the steady-state current density, $i_{\infty}$, the effective diffusion coefficient, $D_{\text {eff, }}$ and the apparent subsurface hydrogen concentration, $C_{\text {eff, }}$ of the steels obtained in the permeation tests using Expressions (1) and (2), respectively. Note that the value of the effective hydrogen diffusivity is 15 times lower in the $\mathrm{H} 8$ steel, although the subsurface hydrogen concentration is about 10 times higher. The highly stressed, hard tempered martensite microstructure of the $\mathrm{H} 8$ steel, with more effective reversible and irreversible hydrogen traps, may justify these results.

Table 3 also gives the hydrogen concentration measured on the samples pre-charged in the highpressure hydrogen reactor, $\mathrm{C}_{\mathrm{HO}}$ (initial hydrogen content) and $\mathrm{C}_{\mathrm{Hf}}$ (strongly trapped or residual hydrogen after a long time stay at room temperature), obtained using the LECO DH603 hydrogen analyser. The difference between these values, $\mathrm{C}_{\mathrm{HO}}-\mathrm{C}_{\mathrm{Hf}}$, is the diffusible hydrogen. Once again, much higher hydrogen contents were likewise measured in the $\mathrm{H} 8$ steel.

\begin{tabular}{ccccccc}
\hline \multicolumn{5}{c}{ Permeation tests } & \multicolumn{3}{c}{ Desorption tests } \\
\hline Steel & $\mathrm{i}_{\infty}\left(\mu \mathrm{A} \mathrm{cm}^{-2}\right)$ & $\mathrm{D}_{\text {eff }}\left({\left.\mathrm{x} 10^{-11} \mathrm{~m}^{2} / \mathrm{s}\right)}\right.$ & $\mathrm{C}_{\text {eff }}(\mathrm{ppm})$ & $\mathrm{C}_{\mathrm{HO}}(\mathrm{ppm})$ & $\mathrm{C}_{\mathrm{Hf}}(\mathrm{ppm})$ & $\mathrm{C}_{\mathrm{HO}}-\mathrm{C}_{\mathrm{Hf}}(\mathrm{ppm})$ \\
\hline $\mathrm{S} 355$ & 43.2 & 130 & 0.65 & 0.63 & 0.46 & 0.17 \\
$\mathrm{H} 8$ & 51.7 & 8.5 & 6.57 & 1.30 & 0.60 & 0.70 \\
\hline
\end{tabular}

Table 3. Steel properties derived from permeation tests and desorption tests conducted on high pressure hydrogen pre-charged samples

\subsection{Fracture toughness}

Figure 4 shows the J-R curves obtained under the different test conditions for the two steels. Fracture toughness results obtained with standard tests $\left(J_{I C}\right)$ and with hydrogen pre-charged specimens $\left(\mathrm{J}_{\mathrm{ICH}}\right)$, as well as embrittlement indexes under each tested condition and values of the J-R curve slopes (dJ/da) for crack growth from $0.5 \mathrm{~mm}$ to $1.5 \mathrm{~mm}$, are shown in Table 4 .

\begin{tabular}{ccccc}
\hline Steel & Displacement rate $(\mathrm{mm} / \mathrm{min})$ & $\mathrm{J}_{\mathrm{IC}} / \mathrm{J}_{\mathrm{ICH}}\left(\mathrm{kJ} / \mathrm{m}^{2}\right)$ & $\mathrm{HEI}(\%)$ & $\mathrm{dJ} / \mathrm{da}\left(\mathrm{MJ} / \mathrm{m}^{3}\right)$ \\
\hline S355 uncharged & 0.1 & $750 \pm 20$ & - & 493 \\
\hline \multirow{3}{*}{ S355, hydrogen pre-charged } & 0.1 & $306 \pm 10$ & 59 & 240 \\
& 0.01 & $297 \pm 14$ & 60 & 207 \\
& 0.001 & $247 \pm 16$ & 67 & 207 \\
\hline H8 uncharged & 0.1 & $450 \pm 15$ & - & 312 \\
\hline & 0.1 & $260 \pm 13$ & 42 & 165 \\
H8, hydrogen pre-charged & 0.01 & $230 \pm 13$ & 49 & 107 \\
& 0.001 & $40 \pm 18$ & 91 & 24 \\
\hline
\end{tabular}

Table 4. Fracture toughness results and embrittlement indexes 

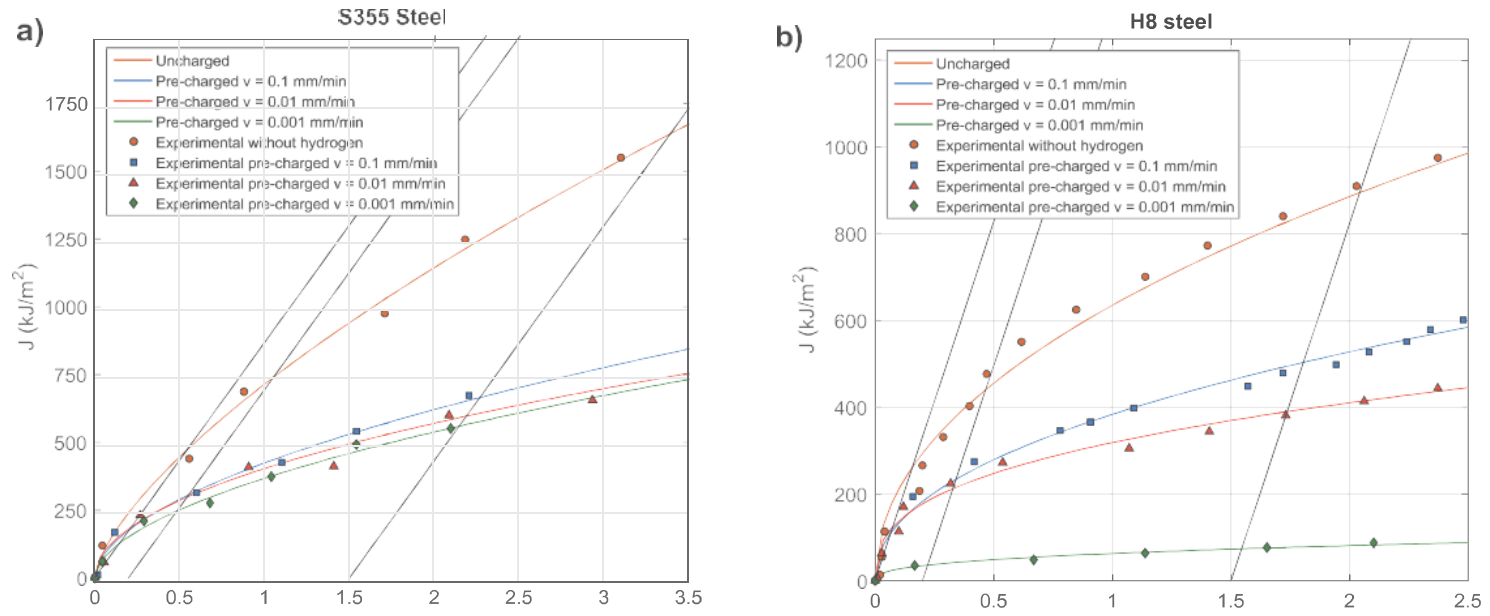

Figure 4. Fracture toughness versus crack growth or J-R curves; a) S355 steel, b) H8 steel

As can be seen, the presence of hydrogen produces a considerable decrease in the fracture toughness of both steels. However, the loading rate has very different effects on the two materials.

The presence of hydrogen also led to significant changes in the fracture micromechanisms observed on the failure surfaces of the tested specimens, as shown in Figures 5 to 8 . The fracture surfaces of the specimens of both steels tested without hydrogen (Figures 5 and 6) showed a fully ductile fracture surface, where the initiation, growth and coalescence of microvoids was the characteristic failure micromechanism.

The ductile fracture micromechanism still remains in most of the fracture surface of the precharged S355 steel samples, which, regardless of the applied displacement rate, only exhibit some signs of embrittlement (cleavage fracture micromechanism) in a small region located just at the beginning of the stable crack growth, observed in the fracture toughness test (Figure 7).

The signs of hydrogen embrittlement at the onset of crack growth are much more noticeable in the case of the pre-charged $\mathrm{H} 8$ steel specimens, with the brittle surface area clearly increasing as the displacement rate decreases, Figure 8 , until a fully brittle crack growth region is observed under the lowest displacement rate $(0.001 \mathrm{~mm} / \mathrm{min})$, as can be seen in Figure $8(e, f)$. Brittle fracture of this steel exhibits the appearance of a transgranular fracture surface or quasi-cleavage, usually referred to as plasticity-related hydrogen induced cracking (PRHIC) in quenched and tempered martensitic steels [30]. The PRHIC mechanism is operative in low alloy quenched and tempered steels in hydrogen gas and is sometimes called tearing topography surface or TTS. This is described as a fracture surface characterised by ductile micro-plastic tearing on a very fine scale, along martensite block and packet interphases [30, 31].
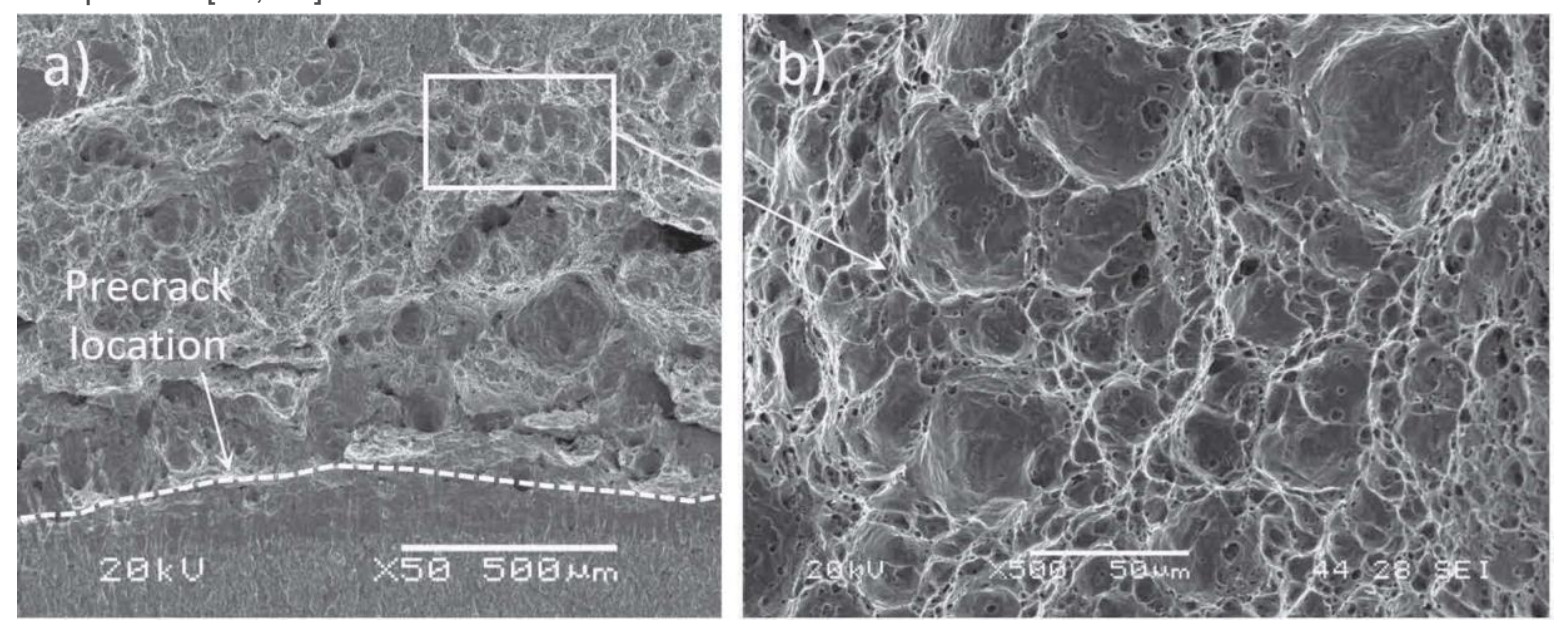

Figure 5. S355 fracture surfaces of uncharged specimens: a) General view. b) Ductile fracture 

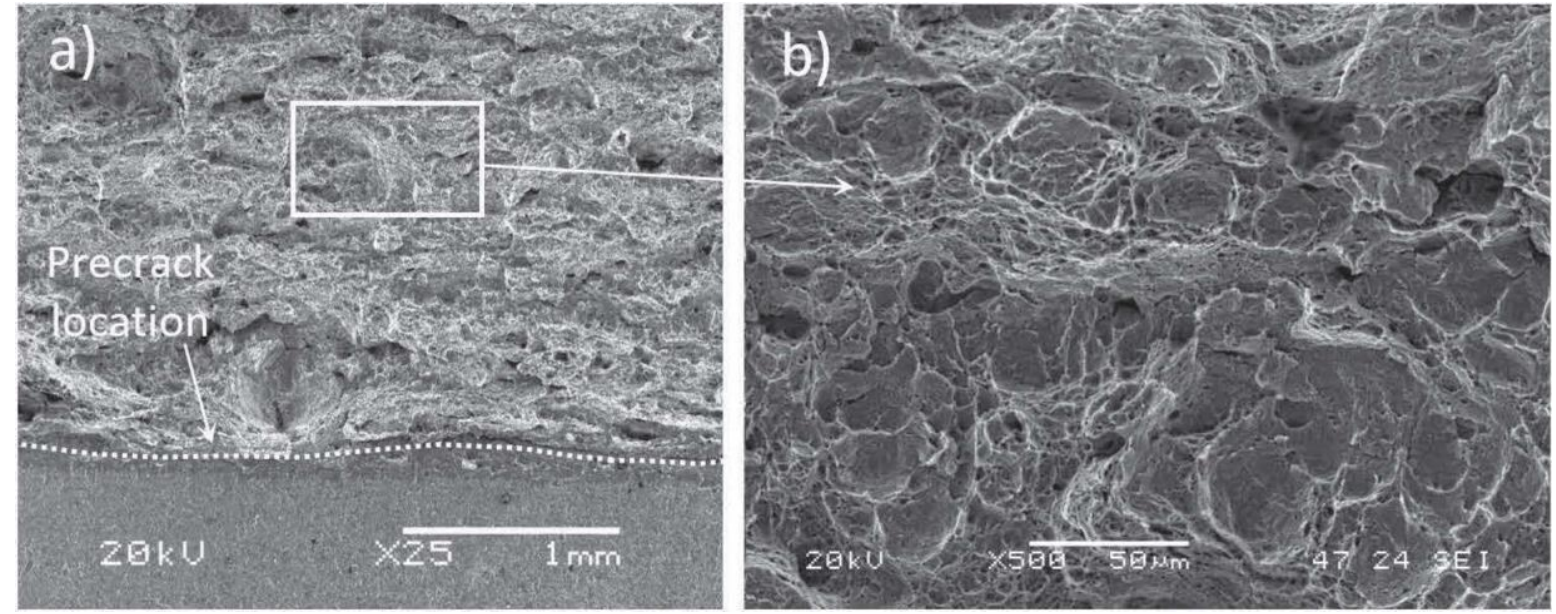

Figure 6. H8 fracture surfaces of uncharged specimens: a) General view. b) Ductile fracture
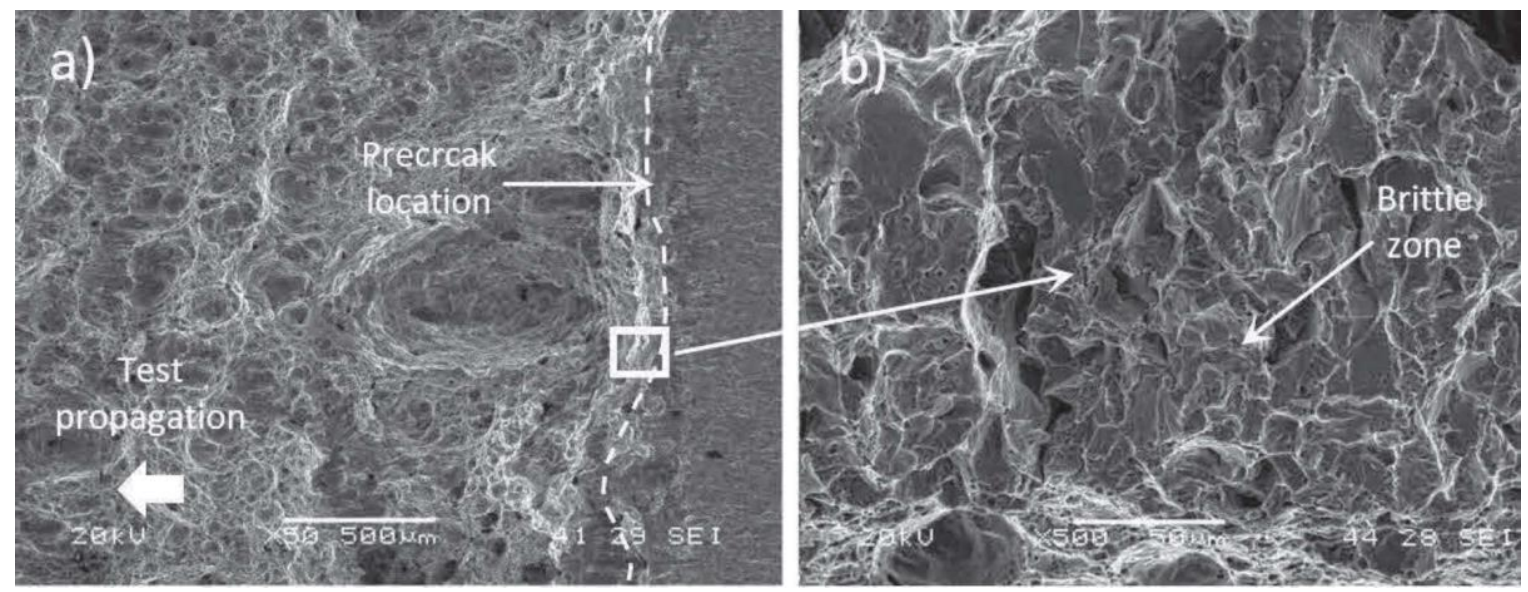

Figure 7. S355 fracture surfaces of hydrogen pre-charged specimens: a) General appearance. b) Brittle fracture (cleavage) at the initiation of crack growth, $v=0.1 \mathrm{~mm} / \mathrm{min}$ 

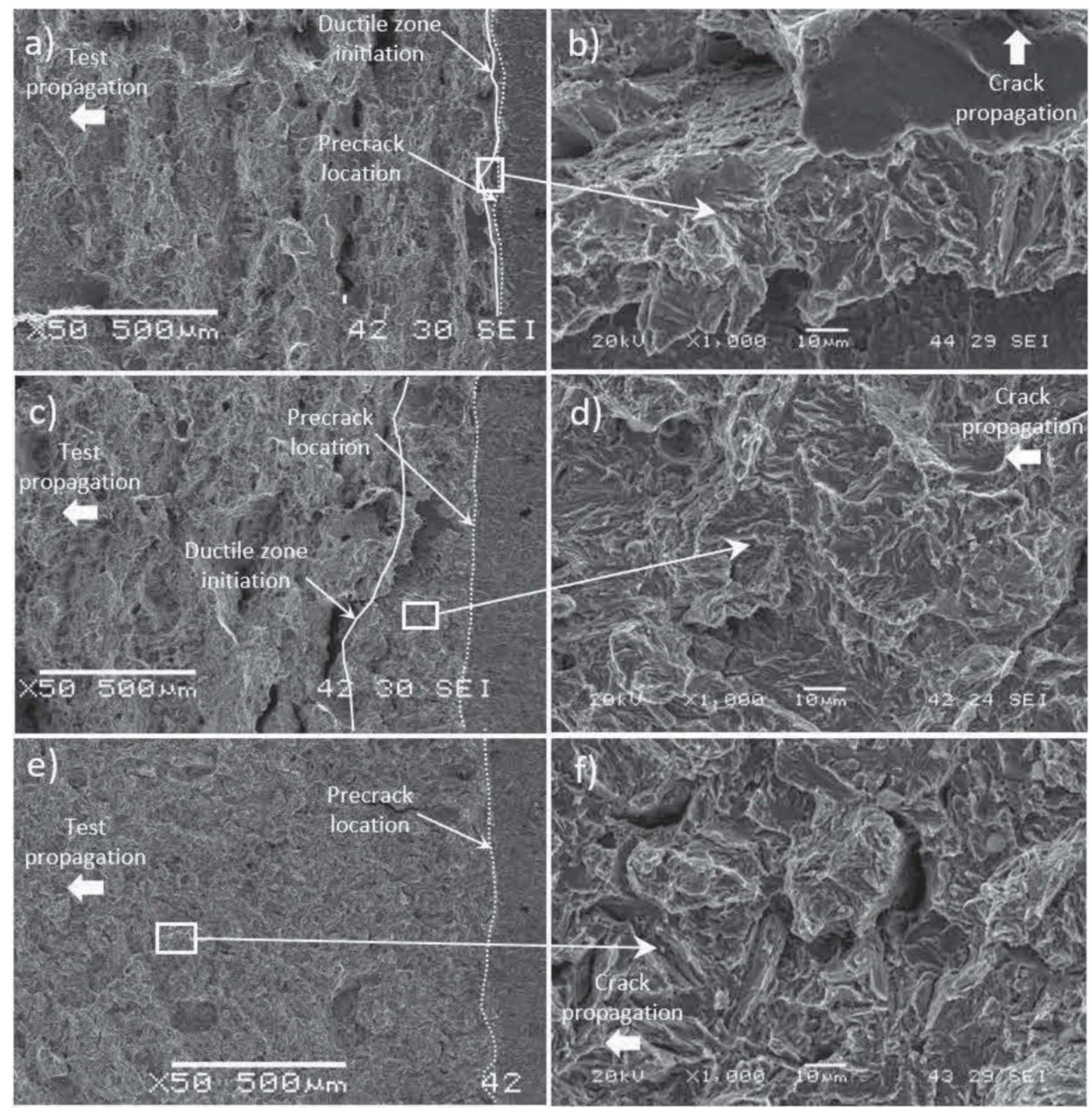

Figure 8. H8 fracture surfaces of hydrogen pre-charged specimens. a) General view, v=0.1 mm/min, b) Brittle fracture (PRHIC), $v=0.1 \mathrm{~mm} / \mathrm{min} \mathrm{c}$ ) General view, $v=0.01 \mathrm{~mm} / \mathrm{min}, \mathrm{d})$ Brittle fracture (PRHIC), $v=0.01$ $\mathrm{mm} / \mathrm{min}, \mathrm{e}$ ) General view, $v=0.001 \mathrm{~mm} / \mathrm{min}, \mathrm{f}$ ) Brittle fracture (PRHIC), $v=0.001 \mathrm{~mm} / \mathrm{min}$.

\section{Discussion}

It is worth noting that the presence of internal hydrogen produces a significant decrease in the fracture toughness of both steels, obtaining embrittlement indexes of between 40 and $90 \%$ for the different displacement rates. Moreover, the different behaviour exhibited by the two steels is also worthy of note: in the case of the $\mathrm{H} 8$ steel, hydrogen embrittlement progressively increased as the test displacement rate decreased, whereas in the case of the $\mathbf{S} 355$ steel, the displacement rate barely affected hydrogen embrittlement.

Furthermore, hydrogen does not only influence the fracture toughness value at the onset of crack growth $\left(\mathrm{J}_{\mathrm{IC}}\right)$, but also affects the slope of the J-R curves. This slope was much flatter (with a lower tearing modulus) when the steels were tested with internal hydrogen (Figure 4), results which are quantitatively expressed in Table 4.

In order to justify the fracture toughness results obtained in this study, the stress and strain distribution existing ahead of a cracked, stress-loaded, elasto-plastic material (SENB specimen) should first of all be recalled. Applying continuum plasticity theory $[32,33]$ in a cracked body of an elasto-plastic material, the stress reaches a peak located at a distance $\mathrm{x}=\mathrm{J} / \sigma_{\mathrm{ys}}$ from the crack tip. Moreover, local strain presents a singularity at the crack tip, reaching very high values ( $\left.\delta_{0 \rightarrow}>10 \%\right)$ at 
approximately half of the maximum stress distance $\left(\mathrm{J} / \mathrm{Z}_{\mathrm{ys}}\right)$, where the dislocation density multiplies, giving rise to high local hydrogen accumulation. The maximum levels of the normal opening stress, $\sigma \quad \mathrm{yy}$, and the hydrostatic stress, $\mathrm{H}$, are respectively around $3 \Phi_{\mathrm{ys}}$ and $2.5_{\mathrm{ys}}$. Additionally, hydrogen located in the surroundings of the crack will diffuse up to the process zone located just ahead of the crack tip (driven by the high hydrostatic stress existing at the crack front, where it is also trapped by dislocations produced in the plastic strained zone), where hydrogen atoms will accumulate, thereby giving rise to the phenomenon of embrittlement (hydrogen enhanced decohesion of internal interphases, HEDE). According to Oriani s theory [34], hydrogen atoms are attracted by the hydrostatic stress existing ahead of the crack until an equilibrium hydrogen concentration, $\mathrm{C}_{\text {Heq, }}$ given by Equation (4), is reached:

$$
C_{H e q}=C_{H \text { dif }} e^{\left(\sigma_{H} V_{H} / R T\right)}
$$

where $\mathrm{C}_{H \text { dif }}$ is the diffusible hydrogen existing in the steel microstructure, and $V_{H}$ is the partial molar volume of hydrogen, which can be approximated by $2 \cdot 10^{-6} \mathrm{~m}^{3} / \mathrm{molH}$ in a ferritic microstructure. Table 5 shows the values of the equilibrium hydrogen concentration at the crack tip, $\mathrm{C}_{\text {Heq, obtained for }}$ each steel by applying Equation (4). Note that the equilibrium hydrogen concentration present ahead of the crack in the S355 steel is very small compared with that of the H8 steel.

On the other hand, the available effective diffusion distance, $\mathrm{xH}_{\mathrm{H}}$, for the movement of hydrogen atoms during the fracture test can be approximated by Expression (5), considering unidirectional hydrogen diffusion towards the crack front in this case. This expression, in which $D_{\text {eff }}$ is the diffusion coefficient of the material and $t$ is the elapsed time, can be used to compare the effective diffusion distance at a certain point in the tests, such as the onset of crack growth ( $\left.\mathrm{J}_{\mathrm{lc}}\right)$ in the fracture toughness tests.

$$
x_{H}=\sqrt{D_{\text {eff }} t}
$$

The testing time needed to reach the JIC value (corresponding to the onset of crack growth), tıs, and the effective diffusion distance for hydrogen, $\mathrm{xH}$, calculated for the aforementioned time by means

\begin{tabular}{|c|c|c|c|c|}
\hline Steel & $\mathrm{C}_{\mathrm{Heq}}(\mathrm{ppm})$ & Test rate & tлıс (h) & $\mathrm{XH}_{\mathrm{H}}(\mathrm{mm})$ \\
\hline S355 & & $\mathrm{v}=0.1 \mathrm{~mm} / \mathrm{min}$ & 0.3 & 1.19 \\
\hline$\left(\sigma_{\mathrm{ys}}=390 \mathrm{MPa}\right)$ & 0.37 & $\mathrm{v}=0.01 \mathrm{~mm} / \mathrm{min}$ & 3.3 & 3.93 \\
\hline$\left(D_{\text {eff }}=1310^{-10} \mathrm{~m}^{2} / \mathrm{s}\right)$ & & $\mathrm{v}=0.001 \mathrm{~mm} / \mathrm{min}$ & 28.4 & 11.45 \\
\hline $\mathrm{H} 8$ & & $\mathrm{v}=0.1 \mathrm{~mm} / \mathrm{min}$ & 0.2 & 0.25 \\
\hline$\left(\sigma_{v g}=790 \mathrm{MPa}\right)$ & 3.44 & $\mathrm{v}=0.01 \mathrm{~mm} / \mathrm{min}$ & 1.7 & 0.72 \\
\hline$\left(D_{\text {eff }}=8.510^{-11} \mathrm{~m}^{2} / \mathrm{s}\right)$ & & $\mathrm{v}=0.001 \mathrm{~mm} / \mathrm{min}$ & 5.2 & 1.26 \\
\hline
\end{tabular}
of Expression (5), are also shown in Table 5.

Table 5. Hydrogen concentration at the crack tip, $\mathrm{C}_{\text {Heq, }}$, elapsed time for the onset of crack growth, $\mathrm{t}_{\mathrm{I}}$, and effective diffusion distance, $\mathrm{x}_{\mathrm{H}}$

It is worth noting that when the steels are tested at the highest displacement rate $(\mathrm{v}=0.1 \mathrm{~mm} / \mathrm{min})$, hydrogen has only a few minutes (20 minutes in the S355 steel and 12 minutes in the H8 steel) to diffuse to the process zone for the initiation of crack growth. When the applied test rate is ten times slower $(\mathrm{v}=0.01 \mathrm{~mm} / \mathrm{min})$, the time required to reach the onset of crack growth also increases correspondingly (3.3 hours for S355 and 1.7 hours for the H8 steel). However, when the test displacement rate is once again decreased ten more times, the $\mathrm{H} 8$ steel needs 10 hours to initiate crack growth, while almost 30 hours are needed for the 355 steel.

The aforementioned major difference in the time needed for the initiation of crack growth can be clearly appreciated by comparing the load-LLD curves of the two steels tested at the different test displacement rates, as shown in Figure 9. As can be seen, while the hydrogen pre-charged S355 steel (Figure 9.a) tested at the lowest displacement rate still shows a quite high toughness value (a specimen displacement of almost $3 \mathrm{~mm}$ is needed for the onset of crack growth), the hydrogen precharged $\mathrm{H} 8$ steel (Figure 9.b) shows a relatively fast onset of crack growth (the point indicated in the figure near the peak of the curve), corresponding to a specimen displacement of around $0.4 \mathrm{~mm}$. 
a)

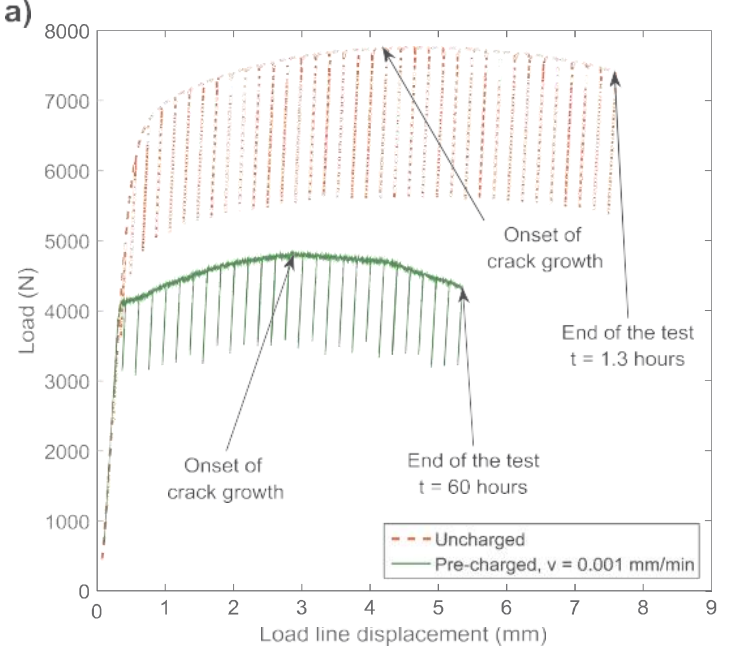

b)

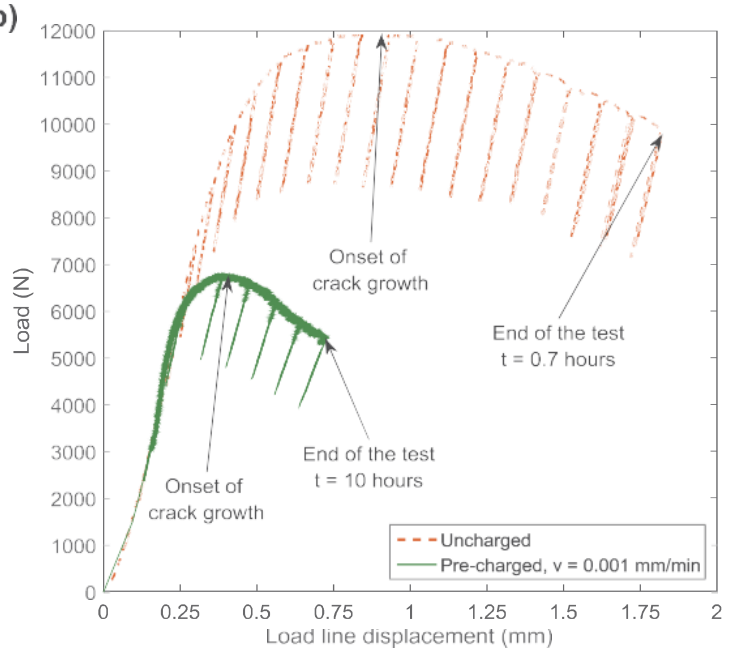

Figure 9. a) Load-LLD curves of S355 steel, b) Load-LLD curves of H8 steel. Uncharged and hydrogen charged specimen under $\mathrm{v}=0.001 \mathrm{~mm} / \mathrm{min}$

On the basis of all these results, it is reasonable to assume that very high hydrogen accumulation took place at the crack front of the hydrogen pre-charged $\mathrm{H} 8$ steel tested at the lowest displacement rate $(\mathrm{v}=0.001 \mathrm{~mm} / \mathrm{min})$. This accumulation of hydrogen probably reached nearly the maximum equilibrium concentration, $3.44 \mathrm{ppm}$, as there was sufficient time for hydrogen diffusion to reach the crack front, even in the case of hydrogen located quite far from it, as effective hydrogen diffusion distances are larger than $1 \mathrm{~mm}(1.26 \mathrm{~mm}$, Table 5). This explains why the high strength $\mathrm{H} 8$ steel showed a very low $\mathrm{J}_{\mathrm{lc}}$ fracture toughness under these conditions, with a hydrogen embrittlement index above $90 \%$ and a flat $\mathrm{J}-\Delta$ a curve. Observation of the fracture surface of this specimen also revealed a fully brittle micromechanism (PRHIC) occurring from the start through to the end of crack growth (Figure $8 \mathrm{e}, \mathrm{f}$ ). Using the same steel, when the displacement rate increases to 0.01 and to 0.1 $\mathrm{mm} / \mathrm{min}$, the required time for hydrogen accumulation ahead of the crack and effective diffusion distances progressively decrease and hence the hydrogen content at the crack front significantly decreases. In these cases, hydrogen embrittlement is progressively lower and the extension of the brittle fracture micromechanism is limited to the crack growth onset region (Figure 8).

In contrast to the $\mathrm{H} 8$ steel, the hydrogen embrittlement indexes of the lower strength S355 steel were found to be barely dependent on the test displacement rate in the fracture toughness tests performed with internal hydrogen. In these tests, the maximum equilibrium hydrogen concentration in the crack front region was about ten times lower (Table 5) due to the relatively low diffusible hydrogen present in the steel and its relatively low yield strength. As the hydrogen diffusion coefficient of this steel is 15 times higher than that of the $\mathrm{H} 8$ steel, effective distances for hydrogen diffusion from 1.2 to $11.5 \mathrm{~mm}$ were calculated for the three tested displacement rates. In this respect, it is worth noting that the effective distance for hydrogen diffusion in the S355 steel tested at the highest displacement rate is similar to that of the $\mathrm{H} 8$ steel tested under the lowest displacement rate (Table 5). It can thus be postulated that, even when the $S 355$ steel is tested at the highest displacement rate $(\mathrm{V}=0.1 \mathrm{~mm} / \mathrm{min})$, the maximum equilibrium hydrogen concentration in the crack front region can be reached and hence the use of slower testing rates barely changes the fracture behaviour of this steel. This is because more time is available for hydrogen accumulation and, under these circumstances, no significant change in the fracture micromechanism would be expected in this case.

\section{Conclusions}

The effect of internal hydrogen on the fracture toughness behaviour of two structural steels, S355 and H8, was studied by means of single edge bend specimens which were hydrogen precharged in a high-pressure gaseous environment. The displacement rate applied in the tests was modified in order to analyse the influence of this test parameter. The following conclusions can be drawn from the study: 
- Gaseous hydrogen pre-charging is a valid and suitable method to introduce hydrogen in steels in order to study hydrogen embrittlement phenomena at room temperature by means of mechanical tests; in this case, by means of fracture toughness tests.

- Hydrogen accumulation ahead of the crack increases with steel yield strength, while the microstructure of the steel also has a significant influence on the hydrogen diffusion coefficient. It can also explain the observed influence that the displacement rate has on the fracture toughness results, giving rise to a modification of the fracture micromechanism from a ductile micromechanism (microvoid coalescence) in the absence of hydrogen to brittle micromechanisms (cleavage or PRHIC) due to hydrogen decohesion of internal interphases when a critical hydrogen concentration is reached.

- It has been demonstrated that hydrogen embrittlement increases with increasing steel strength and as the test displacement rate used in the fracture toughness tests decreases. As regards the steel grade and test conditions, however, an embrittlement limit is reached. Under the experimental conditions employed in this study, a relatively high displacement rate of $0.1 \mathrm{~mm} / \mathrm{min}$ is sufficient to obtain the maximum embrittlement situation for the $\mathrm{S} 355$ steel $(\mathrm{HEI} \cong 60 \%$ ). However, in the case of the stronger $\mathrm{H} 8$ steel, it is necessary to decrease the displacement rate a hundred times, to $0.001 \mathrm{~mm} / \mathrm{min}$, to obtain maximum embrittlement under internal hydrogen ( $\mathrm{HEI} \cong 90 \%)$.

\section{References}

[1] Meng B, Gu C, Zhang L, Zhou C, Li X, Zhao Y, et al. Hydrogen effects on X80 pipeline steel in highpressure natural gas/hydrogen mixtures. Int J Hydrogen Energy 2017;42:7404 -12. doi:10.1016/J.IJHYDENE.2016.05.145.

[2] Nanninga NE, Levy YS, Drexler ES, Condon RT, Stevenson AE, Slifka AJ. Comparison of hydrogen embrittlement in three pipeline steels in high pressure gaseous hydrogen environments. Corros Sci 2012;59:1-9. doi:10.1016/J.CORSCI.2012.01.028.

[3] Dong CF, Liu ZY, Li XG, Cheng YF. Effects of hydrogen-charging on the susceptibility of X100 pipeline steel to hydrogen-induced cracking. Int J Hydrogen Energy 2009;34:9879 -84. doi:10.1016/J.IJHYDENE.2009.09.090.

[4] Tang X, Cheng YF. Quantitative characterization by micro-electrochemical measurements of the synergism of hydrogen, stress and dissolution on near-neutral pH stress corrosion cracking of pipelines. Corros Sci 2011;53:2927-33. doi:10.1016/J.CORSCI.2011.05.032.

[5] Zhao W, Zhang T, He Z, Sun J, Wang Y. Determination of the Critical Plastic Strain-Induced Stress of X80 Steel through an Electrochemical Hydrogen Permeation Method. Electrochim Acta 2016;214:336-44. doi:10.1016/J.ELECTACTA.2016.08.026.

[6] Arafin MA, Szpunar JA. Effect of bainitic microstructure on the susceptibility of pipeline steels to hydrogen induced cracking. Mater Sci Eng A 2011;528:4927-40. doi:10.1016/J.MSEA.2011.03.036.

[7] Park GT, Koh SU, Jung HG, Kim KY. Effect of microstructure on the hydrogen trapping efficiency and hydrogen induced cracking of linepipe steel. Corros Sci 2008;50:1865 -71. doi:10.1016/J.CORSCI.2008.03.007.

[8] Zhao W, Zhang T, Zhao Y, Sun J, Wang Y. Hydrogen permeation and embrittlement susceptibility of X80 welded joint under high-pressure coal gas environment. Corros Sci 2016;111:84 -97. doi:10.1016/J.CORSCI.2016.04.029.

[9] Teus SM, Savvakin DG, Ivasishin OM, Gavriljuk VG. Hydrogen migration and hydrogen-dislocation interaction in austenitic steels and titanium alloy in relation to hydrogen embrittlement. Int $\mathrm{J}$ Hydrogen Energy 2017;42:2424-33. doi:10.1016/J.IJHYDENE.2016.09.212.

[10] Li X, Zhang J, Shen S, Wang Y, Song X. Effect of tempering temperature and inclusions on 
hydrogen-assisted fracture behaviors of a low alloy steel. Mater Sci Eng A 2017;682:359-69. doi:10.1016/j.msea.2016.11.064.

[11] Li X, Zhang J, Wang Y, Li B, Zhang P, Song X. Effect of cathodic hydrogen-charging current density on mechanical properties of prestrained high strength steels. Mater Sci Eng A 2015;641:45-53. doi:10.1016/J.MSEA.2015.06.003.

[12] Moon J, Choi J, Han S-K, Huh S, Kim S-J, Lee C-H, et al. Influence of precipitation behavior on mechanical properties and hydrogen induced cracking during tempering of hot-rolled API steel for tubing. Mater Sci Eng A 2016;652:1206. doi:10.1016/J.MSEA.2015.11.083.

[13] Iwaoka H, Arita M, Horita Z. Hydrogen diffusion in ultrafine-grained palladium: Roles of dislocations and grain boundaries. Acta Mater 2016;107:16877. doi:10.1016/J.ACTAMAT.2016.01.069.

[14] Xu H, Xia X, Hua L, Sun Y, Dai Y. Evaluation of hydrogen embrittlement susceptibility of temper embrittled 2.25Cr-1Mo steel by SSRT method. Eng Fail Anal 2012;19:43 -50. doi:10.1016/J.ENGFAILANAL.2011.08.008.

[15] Bueno AHS, Moreira ED, Siqueira P, Gomes JACP. Effect of cathodic potential on hydrogen permeation of API grade steels in modified NS4 solution. Mater Sci Eng A 2014; 597:117 -21. doi:10.1016/J.MSEA.2013.12.033.

[16] Zhang T, Zhao W, Zhao Y, Ouyang K, Deng Q, Wang Y, et al. Effects of surface oxide films on hydrogen permeation and susceptibility to embrittlement of X80 steel under hydrogen atmosphere. Int J Hydrogen Energy 2018;43:3353-65. doi:10.1016/J.IJHYDENE.2017.12.170.

[17] Song EJ, Baek S-W, Nahm SH, Baek UB. Notched-tensile properties under high-pressure gaseous hydrogen: Comparison of pipeline steel X70 and austenitic stainless type 304L, 316L steels. Int J Hydrogen Energy 2017;42:8075-82. doi:10.1016/J.IJHYDENE.2016.12.069.

[18] Arroyo B, Álvarez JA, Lacalle R, González P. Using Small Punch tests in environment under static load for fracture toughness estimation in hydrogen embrittlement n.d.

[19] Garcia TE, Rodríguez C, Belzunce FJ, Peñuelas I, Arroyo B. Development of a methodology to study the hydrogen embrittlement of steels by means of the small punch test. Mater Sci Eng A 2015;626:34251. doi:10.1016/J.MSEA.2014.12.083.

[20] Singh DK, Singh Raman RK, Maiti SK, Bhandakkar TK, Pal S. Investigation of role of alloy microstructure in hydrogen-assisted fracture of AISI 4340 steel using circumferentially notched cylindrical specimens. Mater Sci Eng A 2017;698:1917. doi:10.1016/J.MSEA.2017.05.056.

[21] Frappart S, Feaugas X, Creus J, Thebault F, Delattre L, Marchebois H. Study of the hydrogen diffusion and segregation into Fe-CAMo martensitic HSLA steel using electrochemical permeation test. J Phys Chem Solids 2010;71:1467-79. doi:10.1016/J.JPCS.2010.07.017.

[22] Rezende MC, Araujo LS, Gabriel SB, dos Santos DS, de Almeida LH. Hydrogen embrittlement in nickel-based superalloy 718: Relationship between $Y^{\prime}+Y^{\prime \prime}$ precipitation and the fracture mode. Int $J$ Hydrogen Energy 2015;40:17075-83. doi:10.1016/J.IJHYDENE.2015.07.053.

[23] Liu Q, Atrens A. Reversible hydrogen trapping in a 3.5NiCrMoV medium strength steel. Corros Sci 2015;96:112-20. doi:10.1016/J.CORSCI.2015.04.011.

[24] Cheng X, Cheng X, Jiang C, Zhang X, Wen Q. Hydrogen diffusion and trapping in V-microalloyed mooring chain steels. Mater Lett 2018;213:11821. doi:10.1016/J.MATLET.2017.11.029.

[25] Thodla R, Piza Paes MT, Gerst B. Hydrogen assisted cracking of AISI 4137M steel in O\&amp;G environments. Int J Hydrogen Energy 2015;40:1705164. doi:10.1016/J.IJHYDENE.2015.07.032.

[26] Zafra A, Peral LB, Belzunce J, Rodriguez C. Effect of hydrogen on the tensile properties of 42CrMo4 steel quenched and tempered at different temperatures. Int J Hydrogen Energy 2018. 
doi:10.1016/j.ijhydene.2018.03.158.

[27] AENOR. UNE-EN ISO 6892-1. Metallic materials - Tensile testing, Part 1: Method of test at room temperature (ISO 6892-1:2016).

[28] ASTM G148-97. Standard practice for evaluation of hydrogenuptake, permeation, and transport in metals by anelectrochemical technique. 2003.

[29] ASTM E1820:2015 - Standard Test Method for Measurement of Fracture Toughness. 2015.

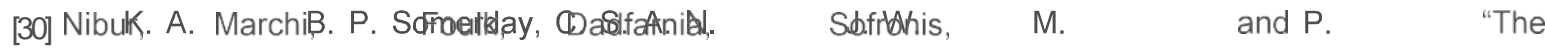
Relationship Between Crack-Tip Strain and Subcritical Cracking Thresholds for Steels in High-Pressure Hydrogen Gas," Metall. Mater. Trans. A, vol. 44A (2013) 248-269.

[31] NagAo, MaMtin, M. MadfarSiefrofhis, M. Mobertson, "The efect of nanonsized (Ti,Mo)C precipitates on hydrogen embrittlement of tempered lath martensitic steels, Acta Mater. (2014) 244-254.

[32] R.M. McMeecking, D.M. Parks, On criteria for J-dominance of crack-tip filds in large-scale yielding, ASTM STP 668, American Society for Testing and Materials, Philadelphia, 1979, 175-194.

[33] P. Sofronis, R.M. McMeecking, Numerical analysis of hydrogen transport near a blunting crack tip, J, Mech. Phys. Solids 37 (1989) 317-350.

[34] Oriani R. A., The diffusion and trapping of hydrogen in steel, Acta Metall. 18 (1970) 147-157.

\section{Acknowledgments:}

The authors would like to thank Know-How Innovative Solutions and the Instituto de Desarrollo Económico del Principado de Asturias (IDEPA) for the support received to carry out Research Project IDE/2016/000283 .

Our thanks also to the Scientific and Technical Service, University of Oviedo, for the use of the SEM JEOL-JSM5600 scanning electron microscope. 